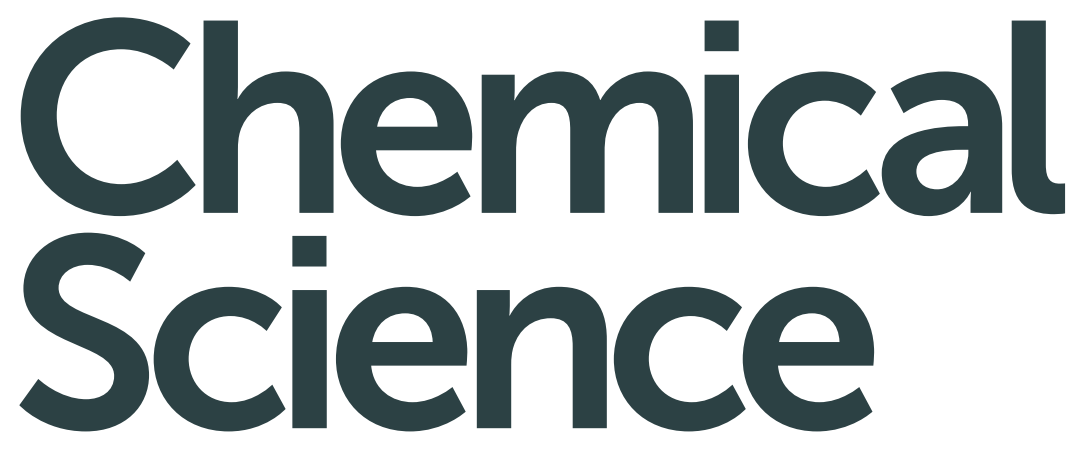

rsc.li/chemical-science

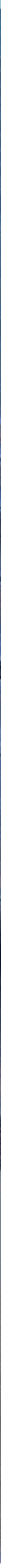

ISSN 2041-6539

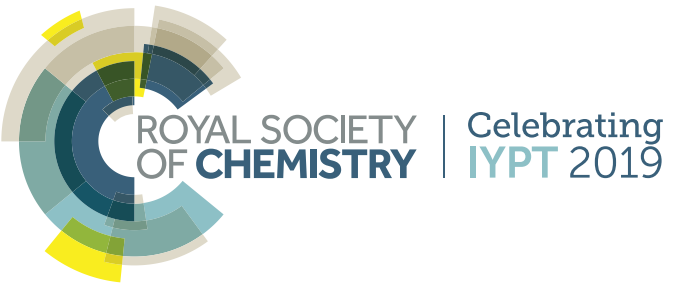

EDGE ARTICLE

Takahiro Ichikawa et al.

Gyroid structured aqua-sheets with sub-nanometer thickness enabling 3D fast proton relay conduction 
Check for updates

Cite this: Chem. Sci., 2019, 10, 6245

¿ All publication charges for this article have been paid for by the Royal Society of Chemistry
Received 9th January 2019

Accepted 31st May 2019

DOI: 10.1039/c9sc00131j

rsc.li/chemical-science

\title{
Gyroid structured aqua-sheets with sub-nanometer thickness enabling 3D fast proton relay conduction $\uparrow$
}

\author{
Tsubasa Kobayashi, (DD ${ }^{a}$ Ya-xin Li, ${ }^{\mathrm{b}}$ Ayaka Ono, ${ }^{a}$ Xiang-bing Zeng $\mathbb{D D}^{\mathrm{b}}$ \\ and Takahiro Ichikawa (D) *ac
}

A polymerizable amphiphile having two zwitterionic head-groups has been designed. This compound coorganizes with an acid, bis(trifluoromethanesulfonyl)imide $\left(\mathrm{HTf}_{2} \mathrm{~N}\right)$, into a gyroid bicontinuous cubic liquidcrystalline phase. In situ polymerization of this phase has been successfully achieved by UV irradiation in the presence of a photoinitiator, yielding a self-standing gyroid-nanostructured polymer film. When the polymer film is placed under different relative humidity conditions or in water, it absorbs water owing to the strong hydration ability of the zwitterionic parts. It has been found that the polymer film preserves the gyroid nanostructure after the water absorption. Based on reconstructed electron density maps, it is assumed that the absorbed water molecules form a 3D continuous network along the gyroid minimal surface, which satisfies several key conditions for inducing fast proton conduction. As expected, such hydrated films show high ionic conductivities in the order of $10^{-1} \mathrm{~S} \mathrm{~cm}^{-1}$ when the water content of the film reaches 15.6 wt $\%$ at $\mathrm{RH}=90 \%$. The high conductivity is attributed to the induction of the Grotthuss mechanism, that is, proton conduction via the hydrogen-bonding network of the incorporated water molecules.

\section{Introduction}

Proton conductive membranes are key materials that play a crucial role in developing a sustainable world because of their versatile utilities in fuel cells, bio-devices, sensors, catalysis, soft robotics, and so on. Following the discovery of proton-conductive fluoropolymers, e.g., Nafion, ${ }^{1,2}$ a variety of proton-conductive membranes have been designed using aromatic polymers, ${ }^{3-6}$ block-copolymers,${ }^{7}$ gels,${ }^{8}$ liquid crystals, ${ }^{9-14}$ metalorganic frameworks, ${ }^{15}$ and some hybrid materials. ${ }^{16}$ It is considered that an ideal proton-conductive membrane should have properties such as high ionic conductivity, high mechanical strength, extremely low fuel $\left(\mathrm{H}_{2}\right.$ gas or $\left.\mathrm{MeOH}\right)$ permeability, and surface morphology forming effective interfaces with catalysts. For the realization of such ideal membranes, there have been intensive demands for the development of an innovative membrane design strategy. We expect that the construction of polymer membranes with 3D-continuous proton conductive pathways should be a promising approach and therefore focus

\footnotetext{
${ }^{a}$ Department of Biotechnology, Tokyo University of Agriculture and Technology, Naka-cho, Koganei, Tokyo, 184-8588, Japan.E-mail: t-ichi@cc.tuat.ac.jp

${ }^{b}$ Department of Materials Science and Engineering, University of Sheffield, Sheffield S1 $3 J D, U K$

'JST, PRESTO, 4-1-8 Honcho, Kawaguchi, Saitama, 332-0012, Japan

$\dagger$ Electronic supplementary information (ESI) available. See DOI: $10.1039 / \mathrm{c} 9 \mathrm{sc} 00131 \mathrm{j}$
}

on the matrix design based on a gyroid surface, ${ }^{17}$ a type of infinite periodic minimal surface.

A gyroid bicontinuous cubic $\left(\mathrm{Cub}_{\mathrm{bi}}\right)$ phase, consisting of two interpenetrating networks separated by a $3 \mathrm{D}$ infinite periodic minimal surface with the space group $I a \overline{3} d$, is typically found in liquid crystals with a lattice parameter of several nanometers. ${ }^{18-24}$ Despite its 3D continuous and periodic structure and hence potential for application, the number of studies on the application of $\mathrm{Cub}_{\mathrm{bi}}$ liquid crystals is still limited. ${ }^{25-39}$ There has been recent progress on our original molecular design principle for creating $\mathrm{Cub}_{\mathrm{bi}}$ liquid crystals. In a representative system, we have employed amphiphilic zwitterions consisting of an organic cation and a sulfonate anion. ${ }^{\mathbf{1 2 , 4 0 - 4 3}}$ Owing to the ability of zwitterions to form adducts with suitably selected acids, it is possible to tune their self-organization behavior in order to form Ia $\overline{3} d$-type (gyroid-type) $\mathrm{Cub}_{\mathrm{bi}}$ liquid-crystalline (LC) assemblies by controlling the addition of acids. Since the $\mathrm{Cub}_{\mathrm{bi}}$ structures formed by the combination of amphiphilic zwitterions and acids possess a hydrophilic gyroid minimal surface where their sulfonic acid groups align densely, they have been expected to be a potential matrix for proton conductive materials.

For the realization of fast proton conduction, one of the most general but advantageous approaches is to create hydrogenbonding networks of water molecules in the matrices because water molecule networks enable fast transport of protons based on a bucket brigade conduction mechanism. This approach is 
effective for our $\mathrm{Cub}_{\mathrm{bi}}$ LC systems to some extent. ${ }^{12}$ However, since the $\mathrm{Cub}_{\mathrm{bi}}$ LC materials have fluidity, it is impossible to introduce a sufficient amount of water molecules into them while maintaining the LC nanostructures. ${ }^{\mathbf{1 2 , 4 0 , 4 1}}$ In general, conversion of fluidic LC materials to solid ones can be achieved by introducing polymerizable groups into LC molecules and subsequent in situ polymerization. ${ }^{44-54}$ In the present study, we report the development of self-standing polymer films with a hydrophilic gyroid minimal surface via in situ polymerization of amphiphilic zwitterions. These polymer films can incorporate water molecules onto the gyroid minimal surface, forming a 3D continuous water network, which leads to the induction of high ionic conductivities in the order of $10^{-1} \mathrm{~S} \mathrm{~cm}^{-1}$.

\section{Results and discussion}

We have designed a new gemini-type polymerizable amphiphile, Diene-GZI (Fig. 1a). Several unique features are incorporated into the molecular design which was inspired by several previous studies on amphiphilic liquid crystals. ${ }^{\mathbf{1 2 , 4 0 , 4 7 , 5 5 - 5 9}}$ One is that the new gemini monomer has zwitterionic head groups consisting of pyridinium cations and sulfonate anions. ${ }^{\mathbf{1 2 , 4 0}} \mathrm{A}$ second is that two single-head/single-tail halves of this monomer are connected via a linker to create a gemini-type amphiphile. ${ }^{55-59} \mathrm{~A}$ third is that polymerizable diene groups are introduced in between the zwitterionic head groups and the long alkyl chains. ${ }^{47}$ The detailed synthesis steps are shown in the ESI (Scheme S1 $\dagger$ ). The thermal behavior of pristine Diene-
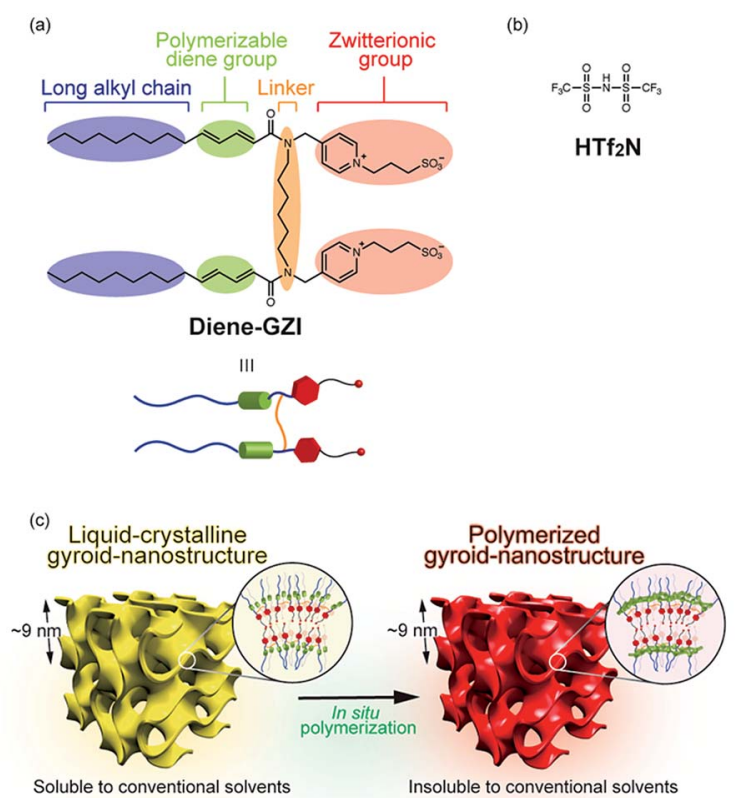

Fig. 1 Design strategy for creating a gyroid-nanostructured matrix. (a) Molecular structure of the polymerizable gemini-type amphiphile (Diene-GZI). (b) Molecular structure of $\mathrm{HTf}_{2} \mathrm{~N}$. (c) Schematic illustration of our strategy for the preparation of a gyroid-nanostructured matrix. The gyroid-nanostructure formed by the self-organization of Diene-GZI has been fixed by in situ radical cross-linking polymerization.
GZI was examined by polarized optical microscopy (POM), differential scanning calorimetry, and X-ray diffraction (XRD) measurements (see the ESI $\dagger$ ). It has been found that pristine Diene-GZI shows thermotropic LC behavior. Although it is difficult to identify the mesophase behavior because thermal polymerization of Diene-GZI starts before isotropization on heating, it is assumed that Diene-GZI forms a layered smectic (Sm) phase through nanosegregation of the zwitterionic and ionophobic parts.

It is of importance that the isotropization temperature and mesophase behavior of Diene-GZI can be tuned by adding some acid and water. By examining the amphotropic (lyotropic and thermotropic) LC behavior of the mixtures of Diene-GZI, acid and water, we have found that Diene-GZI self-organizes into $\mathrm{Cub}_{\mathrm{bi}}$ phases in the presence of suitable amounts of an acid, bis(trifluoromethanesulfonyl)imide $\left(\operatorname{HTf}_{2} \mathrm{~N}\right.$, Fig. 1b), and water. For example, the mixture of Diene-GZI/ $\mathrm{HTf}_{2} \mathrm{~N} /$ water (1.0/0.5/14 by mol) (MX) exhibits a $\mathrm{Cub}_{\mathrm{bi}}$ phase at room temperature (Fig. 1c, left). The formation of the $\mathrm{Cub}_{\mathrm{bi}}$ phase has been characterized by powder XRD measurement and POM observation. The XRD pattern of $\mathbf{M X}$ shows two intense diffraction peaks in the small angle region and the reciprocal $d$-spacing ratio of the two peaks is $\sqrt{6}: \sqrt{ } 8$, which can be indexed as (211) and (220) reflections of an $I a \overline{3} d$-type (gyroid-type) $\mathrm{Cub}_{\mathrm{bi}}$ structure having a lattice parameter a of $94.4 \AA$ (Fig. 2a). No birefringence is observed for MX under POM observation (Fig. 2a, inset), which is also indicative of the formation of the $\mathrm{Cub}_{\mathrm{bi}}$ nanostructure. Based on the insights into the molecular assemblies of the previously designed amphiphilic LC zwitterions, ${ }^{\mathbf{1 2}, 40-43}$ it is most plausible to assume that the sulfonic acid groups of Diene-GZI align regularly on the gyroid minimal surface.

We performed in situ polymerization of $\mathbf{M X}$ in the $\mathrm{Cub}_{\mathrm{bi}}$ state. The detailed procedure is classified into 5 steps and is shown in Fig. 2b: step (I) preparation of MX; step (II) addition of 1 wt\% of 2,2-dimethoxy-2-phenylacetophenone (DMPA) as a radical photo-polymerization initiator; step (III) film formation of the fluidic LC sample on a Teflon substrate; step (IV) UV irradiation; step (V) removal of the film from the substrate. These 5 steps produced a self-standing polymer film (Film$\left.\mathbf{C u b}_{\mathbf{b i}}\right)$. It is noteworthy that the polymerization has progressed while preserving the gyroid-nanostructure. This was confirmed by X-ray measurement and POM observation (Fig. 2a). By performing gravimetric analysis before and after the polymerization process, it was found that Film-Cub $\mathbf{b}_{\mathbf{b i}}$ contains less than 10 wt $\%$ water, while the water content in $\mathbf{M X}$ was $18.7 \mathrm{wt} \%$. The difference in the water content before and after polymerization is attributed to water evaporation during the polymerization process.

To obtain further insight into the nanostructure in Film$\mathbf{C u b}_{\mathbf{b i}}$, synchrotron XRD measurements were performed. By transforming the obtained diffraction patterns into scattered electron waves, we reconstructed the electron density map for

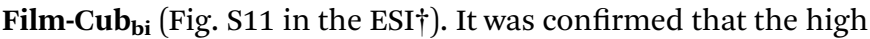
electron density region forms a 3D-continuous domain along the gyroid minimal surface, which is occupied by the zwitterionic part, $\mathrm{HTf}_{2} \mathrm{~N}$ and water. On the other hand, the electron 
(a)

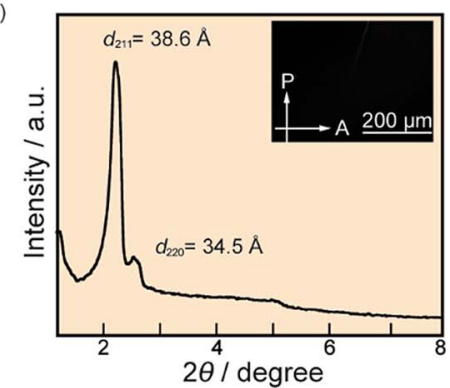

(b)

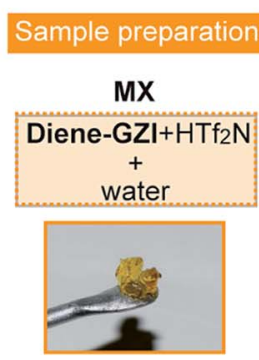

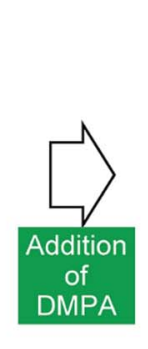
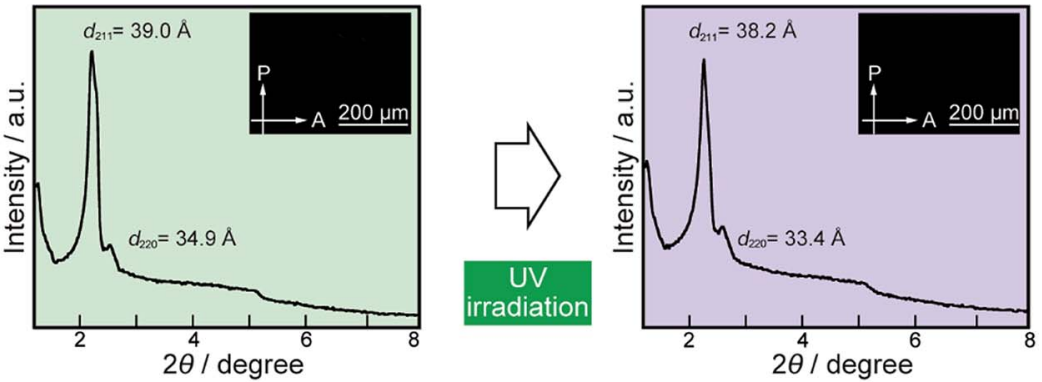

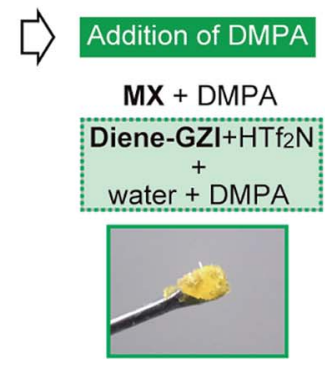

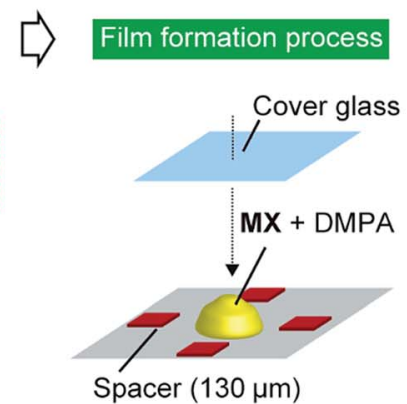

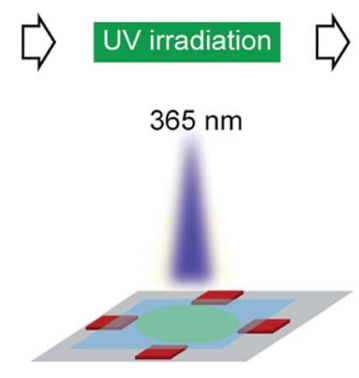

Formation of

self-standing film

Film-Cubbi

Diene-GZI+H $\mathrm{Tf}_{2} \mathrm{~N}$

+
water + DMPA

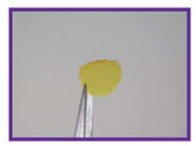

Fig. 2 Preparation procedure for Film-Cub bi having a gyroid-nanostructure. (a) X-ray diffraction (XRD) patterns and polarized optical microscope (POM) textures of MX (background: yellow), MX + DMPA (background: green) and Film-Cubbi (background: purple). There is little

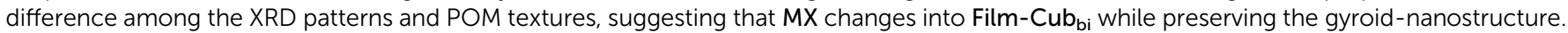
(b) Key steps for converting MX to Film-Cub $\mathrm{b}_{\mathrm{bi}}$. Photographs of MX and MX + DMPA are shown. They are viscous LC phases. After the film formation and UV irradiation steps, MX + DMPA turns into a self-standing polymer film (Film-Cubbi).

lower domains formed by the alkyl chains are observed in the center of 3D-branched nanochannels. The microscopic structure in Film-Cub $\mathbf{b}_{\mathbf{b i}}$ was investigated by scanning electron microscopy (SEM). Floor and cross-sectional views are shown in Fig. S8 in the ESI. $\dagger$ It can be seen that Film-Cub $\mathbf{b u}_{\mathbf{b i}}$ is a homogeneous polymer film with no micro-scale pores, suggesting that the polymerization proceeds homogeneously in the film.

Our aim in the present study is to develop a 3D continuous proton conducting pathway in the film by installing water molecules densely on the gyroid minimal surface. For the realization of this aim, we have examined the structure preserving ability of Film- $\mathbf{C u b}_{\mathbf{b i}}$ under various conditions. To examine the temperature dependence of the gyroid-nanostructure of Film-Cub $\mathbf{b}_{\mathbf{b i}}$, we have carried out XRD measurements with varying temperatures from 30 to $180^{\circ} \mathrm{C}$ on heating and 180 to $30{ }^{\circ} \mathrm{C}$ on cooling (Fig. 3a). It can be seen that little change of the XRD patterns occurs upon heating and cooling, indicating that Film-Cubbi maintains the gyroid-nanostructure in the temperature range whereas the unpolymerized $\mathbf{M X}$ monomer mixture starts to lose the $\mathrm{Cub}_{\mathrm{bi}}$ structure at around $35^{\circ} \mathrm{C}$ (see Fig. S6 in the ESI $\dagger$ ). Focusing on the peak positions, we have found a slight shift of the positions with the increase/decrease of the temperature. For example, the (211) peak gradually shifts to the wide-angle region upon heating from $2 \theta=2.31^{\circ}$ at $30^{\circ} \mathrm{C}$ to $2 \theta=2.36^{\circ}$ at $180{ }^{\circ} \mathrm{C}$. From these values, the cubic lattice parameter " $a$ " in Film-Cub $\mathbf{b}_{\mathbf{b i}}$ was calculated to be $93.5 \AA$ at $30^{\circ} \mathrm{C}$ and $91.7 \AA$ at $180{ }^{\circ} \mathrm{C}$ (Fig. 3a), indicating a shrinkage of the lattice upon heating. This behavior is opposite to what would be expected due to thermal expansion. We assume that the shrinkage of the gyroid structure in Film-Cub $\mathbf{b u}_{\mathbf{b i}}$ results from water drying out of the sample.

To confirm this assumption, gravimetric analysis was performed on Film-Cub $\mathbf{b}_{\mathbf{b i}}$ before and after the heating process. A weight decrease in Film-Cub $\mathbf{b}_{\mathbf{b i}}$ was clearly observed as a function of the increasing temperature. Assuming that the weight decrease results from water drying out of the sample, we
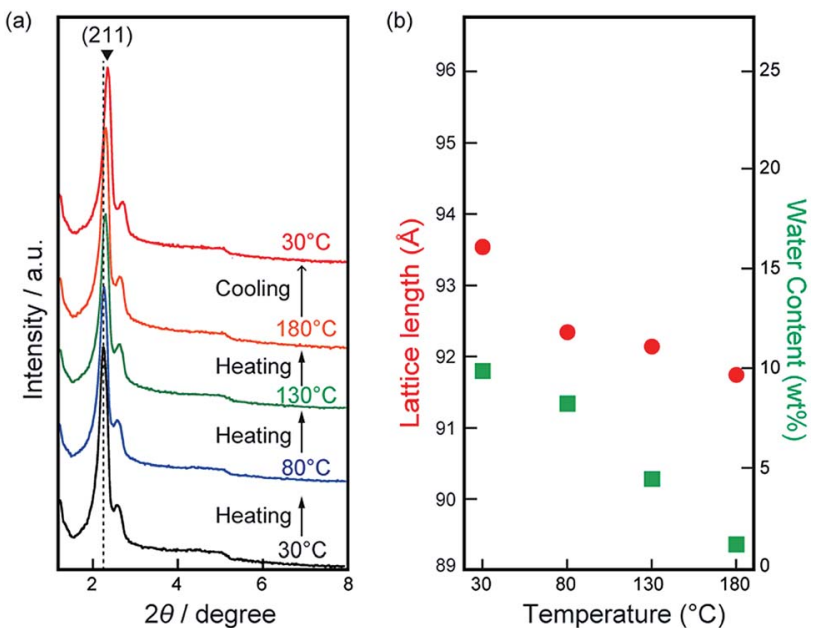

Fig. 3 Stability of the gyroid-nanostructure of Film-Cub $b_{b i}$ at various temperatures. (a) XRD patterns of Film-Cub $\mathrm{b}_{\mathrm{bi}}$ at various temperatures. (b) The cubic lattice lengths and water contents at each temperature are plotted. 
calculated the change of water content in Film-Cub $\mathbf{b u}_{\mathbf{b i}}$, and these values are plotted in Fig. 3b. It can be seen that the water content decreases from $9.9 \mathrm{wt} \%$ in the initial state to $1.2 \mathrm{wt} \%$ at $180{ }^{\circ} \mathrm{C}$. We conclude that water evaporates from Film-Cub $\mathbf{b}_{\mathbf{b i}}$ on heating, which leads to weight loss accompanied by the slight shrinkage of the gyroid-nanostructure. On cooling, further shrinkage of the lattice from 91.7 to $89.6 \AA$ was found when the sample was cooled from 180 to $30{ }^{\circ} \mathrm{C}$, due to thermal contraction. The most notable point is that the gyroid-nanostructure in Film-Cubbi is maintained in the water-drying process, suggesting that the mean positions of the zwitterionic amphiphiles are strongly fixed by cross-linking polymerization while they still have molecular fluctuations. We assume that the creation of the well-stabilized gyroid-nanostructure is attributed to the progress of many more cross-linking reactions that are attainable for gemini-type molecular structures but unattainable for singlehead + single-tail ones. ${ }^{48}$

The next question we addressed is whether it is possible to incorporate a sufficient amount of water molecules into Film$\mathbf{C u b}_{\mathbf{b i}}$ to form a 3D continuous hydrogen-bonding network of water molecules along a gyroid minimal surface. To help answer this question, we have prepared Film-Cub $\mathbf{b}_{\mathbf{b i}}$ and placed it under $\mathrm{RH}$ controlled conditions ( $\mathrm{RH}=50$ to $90 \%$ ) for $12 \mathrm{~h}$ in order to reach an equilibrium state where water absorption and evaporation proceed at the same speed. The water contents $(X \mathrm{wt} \%)$ in the treated films were evaluated from the weight change and henceforth they are denoted as Film-Cubbi $(\boldsymbol{X})$. It was found that the water content $X$ increases from $6.7 \mathrm{wt} \%$ at $\mathrm{RH}=50 \%$ to 15.6 wt $\%$ at $\mathrm{RH}=90 \%$ (Fig. $4 \mathrm{~b}$ ). To confirm whether Film-Cub $\mathbf{b}_{\mathbf{b i}}$ maintains the gyroid structure or not during the water absorption and evaporation processes, XRD measurements have been performed for Film-Cub $\mathbf{b}_{\mathbf{b i}}(\boldsymbol{X})$. Little difference in the shape of the XRD patterns was found for Film-Cub $\mathbf{b}_{\mathbf{b i}}(\boldsymbol{X})$ while a slight shift of the peak positions was observed (Fig. 4a). These results indicate that it is possible to introduce/remove water molecules
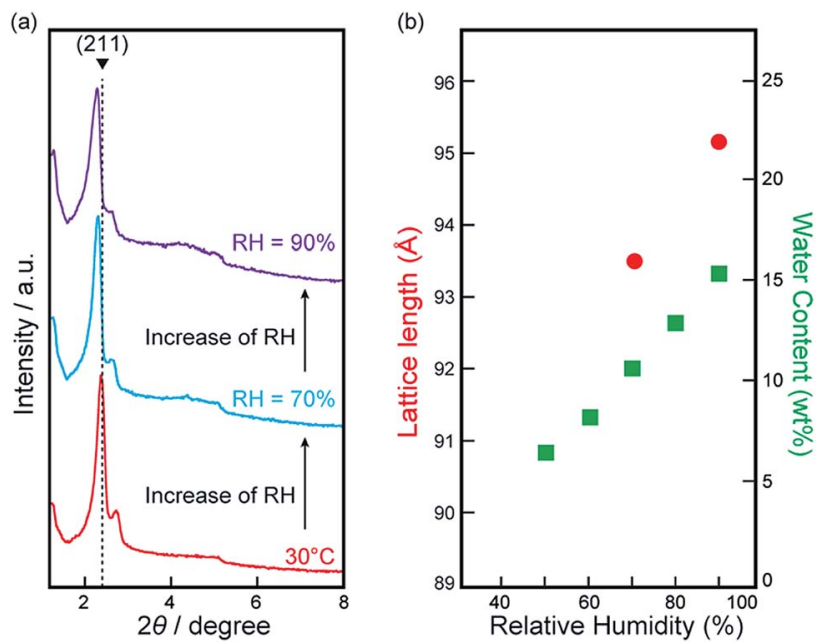

Fig. 4 Stability of the gyroid-nanostructure of Film-Cubbi at various relative humidity $(\mathrm{RH})$ values. (a) XRD patterns of Film-Cubbi at various $\mathrm{RH}$ values. (b) The cubic lattice lengths and water contents at each $\mathrm{RH}$ are plotted. into/from Film-Cub $\mathbf{b i}_{\mathbf{b i}}(\boldsymbol{X})$ by controlling the $\mathrm{RH}$ without distorting the gyroid-nanostructure. In addition, there was no splitting of the (211) reflection peak upon water absorption, suggesting that the incorporated water molecules are homogeneously dispersed around the hydrophilic gyroid minimal surface in Film-Cub bi .

To obtain further insight into the position and state of the incorporated water molecules in the gyroid-nanostructures of Film-Cubbi $(\boldsymbol{X})$, DSC measurement was performed for Film$\mathbf{C u b}_{\mathbf{b i}}$ (15.6). No exothermic and endothermic peak is observed for Film-Cub $\mathbf{b}_{\mathbf{b i}}(\mathbf{1 5 . 6})$ at around $0{ }^{\circ} \mathrm{C}$ on cooling, indicating that almost all the water molecules in the film exist not as free water but as bound water (Fig. 5). The number of water molecules per sulfonate group in Film-Cubbi(15.6) is calculated to be about 5.6. Taking into account the general knowledge that one sulfonic acid group has the ability to strongly interact with up to 8-14 water molecules, ${ }^{\mathbf{6 0}-62}$ it is plausible that the absorbed water molecules are placed exclusively on the gyroid minimal surface where the sulfonate/sulfonic-acid groups of Diene-GZI are aligned densely.

In order to obtain critical information on the positions of the incorporated water molecules, we performed synchrotron XRD measurements on samples of Film-Cub $\mathbf{b}_{\mathbf{b i}}$ containing various amounts of water. The driest sample was obtained by drying at $110^{\circ} \mathrm{C}$ and the wettest sample was prepared by immersing into water. Samples with a whole range of water contents were prepared by tuning these processes. The XRD patterns obtained for these samples clearly show that Film-Cub $\mathbf{b}_{\mathbf{b i}}(\boldsymbol{X})$ can maintain the $\mathrm{Cub}_{\mathrm{bi}}$ periodic structure with the same $I a \overline{3} d$ space group while increasing the water amount leads to expansion of the lattice (Fig. 6). In particular, the lattice parameter increases by $18 \%$ from the driest to the wettest conditions, which corresponds to an increase in the unit cell volume of $63 \%$. Such an increase in the unit cell volume is attributed to the increase in the water content in Film-Cub $\mathbf{b}_{\mathbf{b i}}(\boldsymbol{X})$. The density of the driest sample is measured to be $1.27 \mathrm{~g} \mathrm{~cm}^{-3}$ by means of flotation analysis (Fig. S12 in the ESI $\dagger$ ). Using the measured lattice parameters and water content of the as-prepared, dried Film-

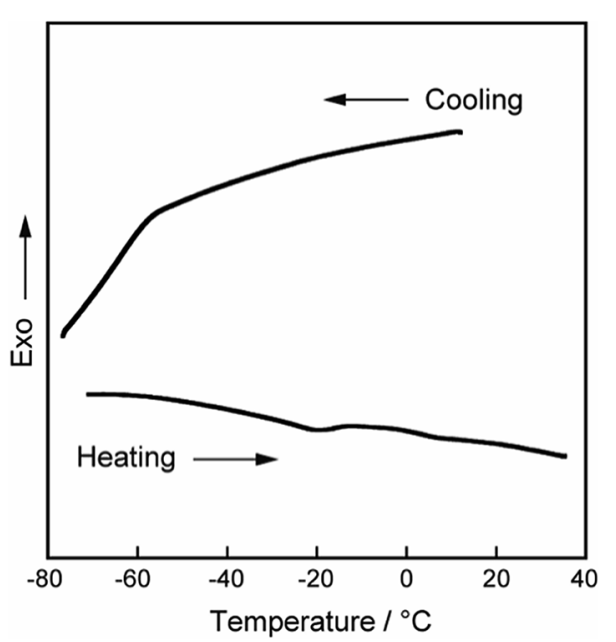

Fig. 5 DSC thermograms of Film-Cub $b_{b i}(15.6)$ on cooling and heating. 


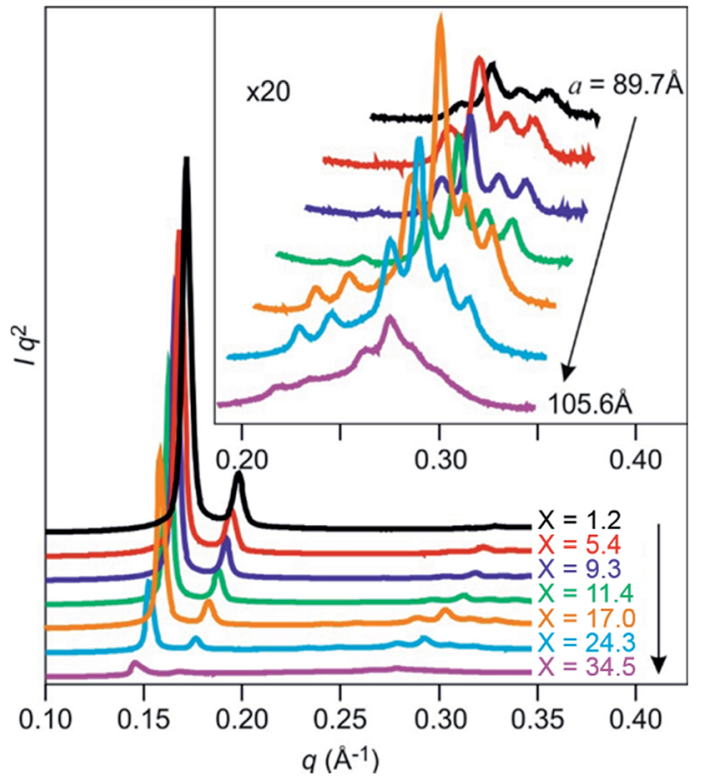

Fig. 6 X-ray diffraction patterns of Film- $\operatorname{Cub}_{\mathrm{bi}}(X)$ with various water contents at $25^{\circ} \mathrm{C}$.

$\mathbf{C u b}_{\mathbf{b i}}(\boldsymbol{X})$ samples, and assuming that the water density in the film is $1.00 \mathrm{~g} \mathrm{~cm}^{-3}$, we have derived a relationship between the lattice parameter and the amount of absorbed water by weight (Table S9 in the ESI $\dagger$ ). It was thus estimated that the water content $X$ in the prepared samples ranged from 1.2 to $34.5 \mathrm{wt} \%$. The derived relationship suggests that the wettest sample has a density of $1.16 \mathrm{~g} \mathrm{~cm}^{-3}$, which is consistent with the experimentally obtained value $\left(1.17 \mathrm{~g} \mathrm{~cm}^{-3}\right)$.

Another noteworthy feature in the XRD patterns is that the relative intensities of the first two diffraction peaks, (211) and (220), decrease dramatically with increasing water content in the Film-Cub $\mathbf{b}_{\mathbf{b i}}(\boldsymbol{X})$ samples. It is expected that the increase in water content would expand the volume of high electron density regions (ionic + water) and reduce the relative volume of the lower electron density regions (alkyl chain); therefore the overall contrast in the structure is reduced leading to weaker diffraction peaks. This assumption is clearly confirmed from reconstructed electron density maps (Fig. 7 and S13 in the ESI $\dagger$ ). The changes of the electron density are visualized with colour changes from red, yellow, green, aqua, and blue to purple as the electron density increases. Focusing on the gyroid minimal surface, it can be seen that, while it is coloured only purple when the water content is low $(X=1.2,5.4$, and 9.3), scattered blue domains appear when the water content is $17.0 \mathrm{wt} \%$, and the blue domains gain $3 \mathrm{D}$ continuity when the water contents are 24.3 and $34.5 \mathrm{wt} \%$. In other words, a blue coloured gyroid minimal surface appears upon water absorption between the purple domains with the highest electron density. This can be explained by assuming that the blue gyroid surface between the purple regions is formed by localization of some water molecules, and the purple domains are composed mostly of the ionic segments with high electron density. We attribute this local segregation between water and the ionic domains to two effects. One is the strong hydrophobicity of the $\operatorname{Tf}_{2} \mathrm{~N}$ anion. The other is the strong hydrophilicity of the sulfonate anion of the zwitterionic parts. The number of water molecules per zwitterionic headgroup on the monomer in the films with 17.0, 24.3, and $34.5 \mathrm{wt} \%$ water can be calculated to be 6.2, 9.8, and 16.0. Recently, there have been several studies on the relationship between the ion structure of various ionic liquids and their water sorption ability. ${ }^{63}$ Considering this general insight, the maximum number of water molecules that form strong interactions with a pyridinium-cation is expected to be lower than 5 . This led us to assume that there is an excess number of water molecules beyond the hydration limitation of the pyridinium cation when the water content $X$ is $\geq 21 \mathrm{wt} \%$. Consequently, the excess water molecules, being bound to the sulfonate groups and/or being shed by the $\mathrm{Tf}_{2} \mathrm{~N}$ anions, form an extremely thin water sheet domain along the gyroid minimal surface. It is worth noting that the blue domain along the gyroid minimal surface can be named a "3D continuous aqua sub-nanosheet".

It is well-known that proton conduction is induced by the combination of two mechanisms, the vehicle and the Grotthuss mechanisms. ${ }^{\mathbf{6 4}, 65}$ The former mechanism is proton migration based on the molecular diffusion of protonated water clusters. The latter mechanism is instantaneous transmittance of protons through water molecule networks as a result of breaking/forming of hydrogen-bonding, which provides exceptionally high-speed ion conduction. This mechanism can be recognized as a kind of Newton's cradle (NC) phenomenon where water molecules act as "balls". Taking into account the geometrical character of a gyroid structure which is composed of patching of saddle-shaped plates, we expect that the present polymer film should act as a novel platform for water molecules to exhibit a 3D NC phenomenon and then show high proton conductivity in the order of $10^{-1} \mathrm{~S} \mathrm{~cm}^{-1}$, which is comparable to the limit value of the Grotthuss mechanism. Generally, it is essential for inducing effective NC phenomena to align "balls" one- or two-dimensionally without any space between them. With this in mind, it is considered that successive proton conduction via the Grotthuss mechanism along the gyroid minimal surface can be induced when water molecules are installed all over the surface (Fig. S14 in the ESI $\dagger$ ). Roughly estimating the number of water molecules that is required to fulfill a gyroid minimal surface in a cubic lattice with a lattice length of $95 \AA$ (see the ESI $\dagger$ ), it is calculated to be about 4000. By converting the number of water molecules per unit cell into the weight ratio, it is expected that over $12 \mathrm{wt} \%$ of the water content is needed at least in the case of Film- $\mathbf{C u b} \mathbf{b}_{\mathbf{b i}}(\boldsymbol{X})$ to cover the gyroid minimal surface.

In order to examine the relationship between the ball filling rate (namely water content) and proton conductivity, impedance measurements were performed for $\mathbf{F i l m}-\mathbf{C u b}_{\mathbf{b i}}(\boldsymbol{X})$ with various water contents. The ionic conductivity $(\sigma)$ values are plotted against the water content $X$ in Fig. 8a. It can be seen that the $\sigma$ values depend largely on the water content. For example, the $\sigma$ of Film-Cub $\mathbf{b u}_{\mathbf{b i}}(\boldsymbol{X})$ is $3.3 \times 10^{-5} \mathrm{~S} \mathrm{~cm}^{-1}$ when $X=6.7 \mathrm{wt} \%$, which is far lower than $10^{-1} \mathrm{~S} \mathrm{~cm}^{-1}$. The conduction mechanism in Film-Cub $\mathbf{b}_{\mathbf{b i}}(\mathbf{6 . 7})$ is thus probably dominated by the vehicle mechanism because the gyroid minimal surface is not fully covered by water molecules enough to induce the 


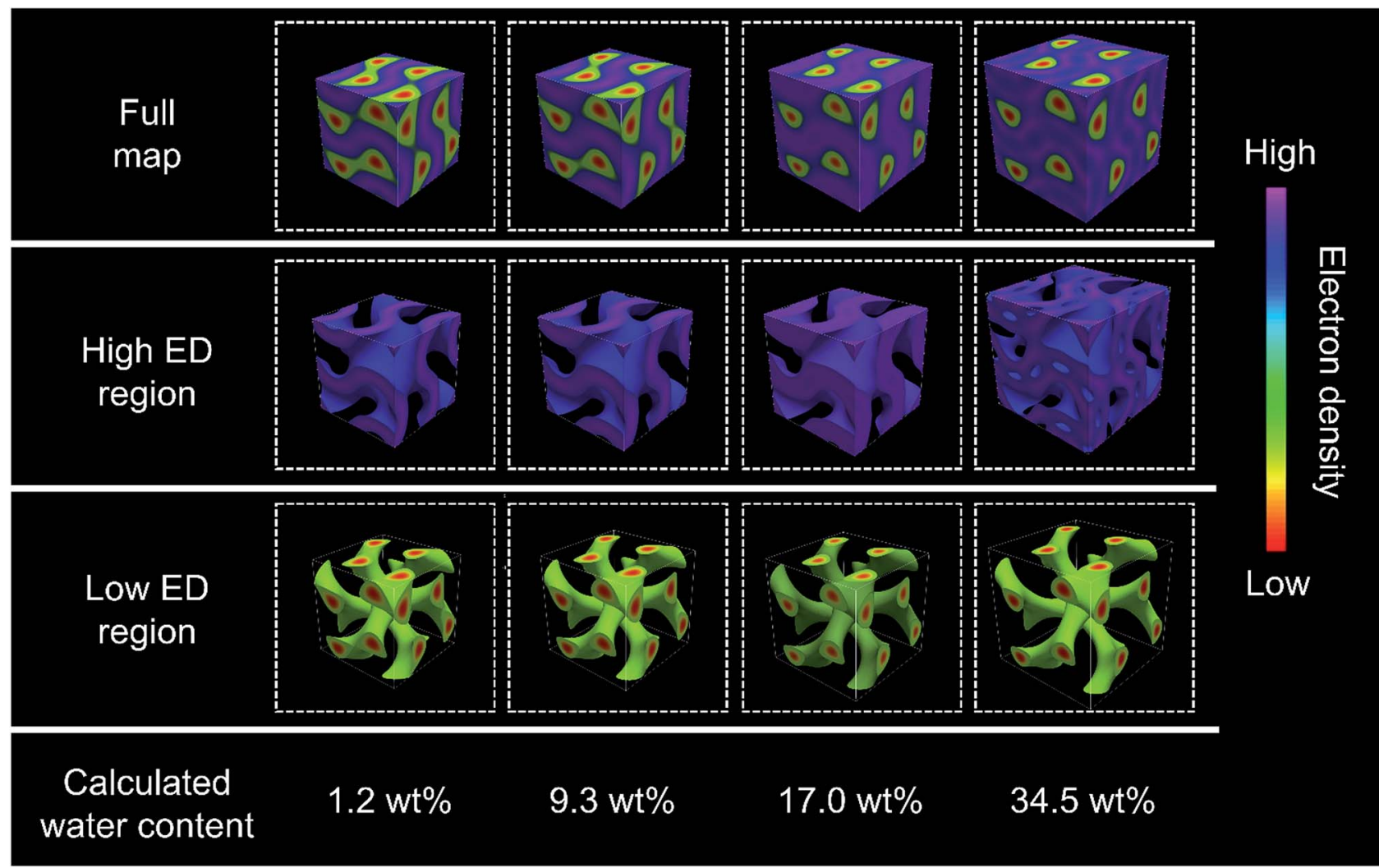

Fig. 7 Reconstructed electron density maps of Film-Cub ${ }_{b i}(X)$ with various water contents. The highest electron density region is coloured with purple. The lowest electron density region is coloured with red.

Grotthuss mechanism. On the other hand, the $\sigma$ of Film$\mathbf{C u b}_{\mathbf{b i}}$ (13.1) is $1.5 \times 10^{-2} \mathrm{~S} \mathrm{~cm}^{-1}$ and that of Film- $\mathbf{C u b}_{\mathbf{b i}}(\mathbf{1 5 . 6})$ is close to $10^{-1} \mathrm{~S} \mathrm{~cm}^{-1}$, which is an achievable value only when protons can be transported based on the Grotthuss mechanism over a long distance. These results led us to conclude that it is possible to induce a NC phenomenon along a gyroid minimal surface by adding an adequate amount of balls to fully cover the surface. We assume that, owing to the 2D nature of the gyroid structure, protons can show 2D NC-type fast transport in local ranges, which develops into $3 \mathrm{D}$ transport in larger ranges as a result of the 3D patching manner of the $2 \mathrm{D}$ plates.

To date, a variety of materials design methods have been employed for improving proton-conductive polymer electrolytes for fuel cell applications. ${ }^{66-68}$ The present materials design should be a new advantageous method for providing a new electrolyte design. Below, we compare the present materials and conventional polymer electrolytes, such as Nafion, from the viewpoint of ion conductive materials. The temperature dependence of $\sigma$ of Film-Cub $\mathbf{b}_{\mathbf{b i}}$ (15.6) was investigated under measurement conditions of a heating rate of $2{ }^{\circ} \mathrm{C} \mathrm{min}^{-1}$ and $\mathrm{RH}$ $=40 \%$. The $\sigma$ linearly increases as temperature increases from ambient temperature to around $70^{\circ} \mathrm{C}$ (Fig. 8b) and it reaches 9.9 $\times 10^{-2} \mathrm{~S} \mathrm{~cm}^{-1}$ at $70^{\circ} \mathrm{C}$, which is comparable to that of highly hydrated Nafion. ${ }^{69}$ The activation energy in this temperature range is calculated to be $2.2 \mathrm{~kJ} \mathrm{~mol}^{-1}$. This low activation energy strongly supports our conclusion that the proton conduction in Film-Cub $\mathbf{b i}_{\mathbf{b i}}$ (15.6) mostly depends on the Grotthuss mechanism.
The activation energy of highly hydrated Nafion has been reported to be $10-15 \mathrm{~kJ} \mathrm{~mol}^{-1}{ }^{68}$ Recently, there have been some reports that hydrogen-bonding networks of water molecules confined under specific conditions, such as in carbon nanotubes and in between mineral layers, exhibit exceptionally high ionic conductivity and low activation energy due to the formation of specifically coordinated structures of water molecules. $^{70,71}$ Considering these examples, there is a possibility that a specific proton conduction mechanism is induced in the present materials in which water molecules are confined exclusively on a gyroid minimal surface.

In order to further discuss the effects of the polymerization on the ion conduction behavior, the $\sigma$ of Film- $\mathbf{C u b}_{\mathbf{b i}}$ (15.6) was compared with that of an analogous non-polymerizable LC system. For such a non-polymerizable LC control sample, a mixture of a mono-type amphiphilic zwitterion with a normal alkyl chain $(\mathbf{N}-\mathbf{M Z I})^{72}$ and $\mathrm{HTf}_{2} \mathrm{~N}$ with a small amount of water was selected. The $\sigma$ of the $\mathbf{N}-\mathbf{M Z I} / \mathrm{HTf}_{2} \mathrm{~N}$ mixture (1.0/1.0 by mol) with $9.4 \mathrm{wt} \%$ water (reported in our previous paper ${ }^{12}$ ) is also plotted in Fig. 8b. Comparing the $\sigma$ of Film-Cub $\mathbf{b}_{\mathbf{b i}}(\mathbf{1 5 . 6 )}$ and that of the N-MZI/HTf ${ }_{2} \mathrm{~N}$ mixture, we found some significant differences. For example, Film-Cub bi $_{\mathbf{b i}}\left(\mathbf{1 5 . 6 )}\right.$ shows a $\sigma$ of $8.4 \times 10^{-2} \mathrm{~S}$ $\mathrm{cm}^{-1}$ at $35^{\circ} \mathrm{C}$, which is about 3 times higher than that of the $\mathbf{N}$ $\mathbf{M Z I} / \mathrm{HTf}_{2} \mathrm{~N}$ mixture. The large difference in $\sigma$ mostly results from the difference in water content. The water content in Film$\mathbf{C u b}_{\mathbf{b i}}$ (15.6) is about twice that in the N-MZI/HTf ${ }_{2} \mathrm{~N}$ mixture. Here it should be noted that, while the $\mathbf{N}-\mathbf{M Z I} / \mathrm{HTf}_{2} \mathrm{~N}$ mixture 
(a)

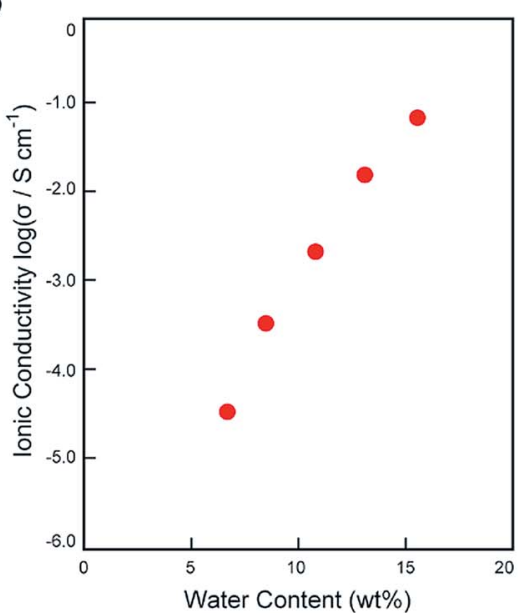

(b)

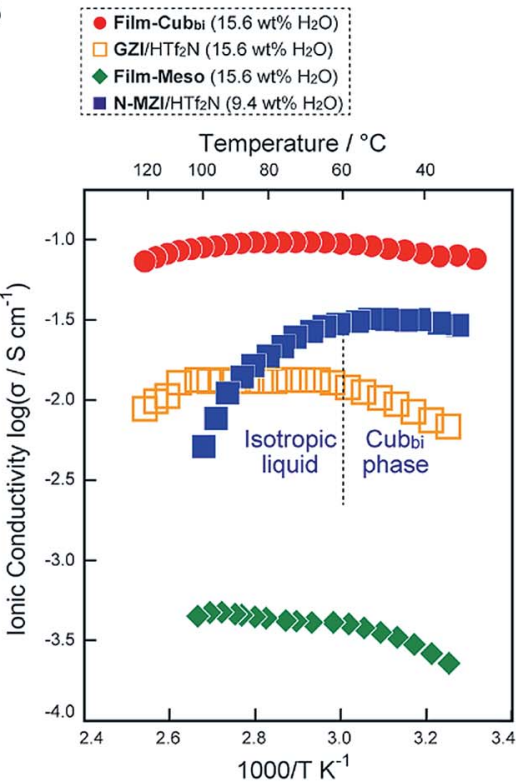

Fig. 8 (a) Ionic conductivity of Film- $\mathrm{Cub}_{\mathrm{bi}}(X)$ against the water content $X$. (b) Arrhenius plot of the ionic conductivity of Film$\mathrm{Cub}_{\mathrm{bi}}(15.6)(-)$. As comparisons, that of $\mathrm{N}-\mathrm{MZI} / \mathrm{HTf}_{2} \mathrm{~N}$ (1.0/1.0 by mol) containing 9.4 wt\% of water ( $\boldsymbol{\square})$, that of Film-Meso ( $)$, and that of the $\mathrm{GZI} / \mathrm{HTf}_{2} \mathrm{~N}$ mixture containing $15.6 \mathrm{wt} \%$ of water $(\square)$ are also plotted.

forms gyroid-nanostructures when the water content is $<10$ $\mathrm{wt} \%$, it is impossible to increase the water content above $10 \mathrm{wt} \%$ for the $\mathbf{N}-\mathbf{M Z I} / \mathrm{HTf}_{2} \mathrm{~N}$ mixture while maintaining its molecular assembled gyroid-nanostructures because the increase of the water content results in phase changes and significant lowering of the isotropization temperature. Another noteworthy point is that the $\sigma$ of the $\mathbf{N}-\mathbf{M Z I} / \mathrm{HTf}_{2} \mathrm{~N}$ mixture abruptly decreases at around $60{ }^{\circ} \mathrm{C}$, which can be explained in two ways. One is the collapse of hydrogen-bonding networks of the water molecules, followed by phase transition to the isotropic phase. The other is decrease of the water content through evaporation. Compared to the ion conduction behaviour of the $\mathbf{N}-\mathbf{M Z I} / \mathrm{HTf}_{2} \mathrm{~N}$ mixture, Film-Cubbi (15.6) shows a gradual decrease of $\sigma$ at temperatures higher than $70{ }^{\circ} \mathrm{C}$. First, it is concluded that the polymerization of the amphiphilic zwitterions results in overcoming the disadvantage of the LC materials that they lose structural benefits in the temperature region higher than their isotropization temperature. Not only does it enhance the structural-benefits, it also contributes to the enhancement of the water-binding ability as a result of the preservation of a unique situation where the sulfonate/sulfonic-acid groups are densely aligned on a continuous surface. As another control sample, we prepared a polymeric sample by polymerizing the Diene-GZI/ $\mathrm{HTf}_{2} \mathrm{~N}$ mixture in a molar ratio of $1: 0.5$ with $1 \mathrm{wt} \%$ of DMPA at $130{ }^{\circ} \mathrm{C}$ in a disordered state under UV irradiation for $1 \mathrm{~h}$. The obtained polymeric sample was mixed with water to obtain a water content of 15.6 wt\% (Film-Meso(15.6)). The absence of a well-ordered nanostructure in Film-Meso(15.6) was confirmed by XRD measurement (see Fig. S15 in the ESI $\dagger$ ). Comparing the $\sigma$ of Film-Cub $\mathbf{b i}_{\mathbf{b i}}$ (15.6) and Film-Meso(15.6), it is notable that Film-Cubbi (15.6) shows higher $\sigma$ than Film-Meso(15.6). For example, the $\sigma$ of Film-Cub $\mathbf{b}_{\mathbf{b i}}(\mathbf{1 5 . 6})$ is $9.7 \times 10^{-2} \mathrm{~S} \mathrm{~cm}^{-1}$, which is 240 times larger than that of Film-Meso(15.6). These results suggest that the presence of the gyroid nanostructure is a critical factor that enhances the contribution of the Grotthuss mechanism in the polymerized amphiphilic zwitterionic systems.

To further confirm the importance of the polymerization for high proton conduction, we prepared a gemini-type amphiphilic zwitterion with normal alkyl chains (GZI, see the ESI $\dagger$ ). By mixing GZI and $\mathrm{HTf}_{2} \mathrm{~N}$ in a 1 : 0.5 molar ratio and adding 15.6 $\mathrm{wt} \%$ of water, a control sample forming a fluidic LC state was prepared. The $\sigma$ of the $\mathbf{G Z I} / \mathrm{HTf}_{2} \mathrm{~N}$ mixture is also plotted in Fig. 8b. It can be seen that the $\sigma$ of Film-Cub $\mathbf{b}_{\mathbf{b i}}(\mathbf{1 5 . 6 )}$ is about an order of magnitude higher than that of the $\mathbf{G Z I} / \mathrm{HTf}_{2} \mathrm{~N}$ mixture. These results lead us to assume that the polymerization of the gemini-amphiphilic zwitterion has an effect on limiting the position of water molecules in the system at the hydrophilic gyroid minimal surface. Consequently, it enhances the macroscopic continuity of hydrogen-bonding networks of water molecules, which enables a more efficient Grotthuss proton conduction mechanism over a long distance.

In addition to these physicochemical properties, the present materials have great potential for exhibiting new advantageous aspects as polymer electrolytes for fuel cells. For example, since the proton conduction pathways in Film-Cub $\mathbf{b}_{\mathbf{b i}}(\boldsymbol{X})$ have $3 \mathrm{D}$ continuity, this film is independent of the formation of "deadends" in proton conduction pathways. Another aspect is that the nanosegregated structure in Film-Cub $\mathbf{b}_{\mathbf{b i}}(\boldsymbol{X})$ should contribute to the formation of an effective interface between catalysts and electrolytes. It is also expected that, by substituting the $\mathrm{Tf}_{2} \mathrm{~N}$ anion with non-fluoridated anions after polymerization, Film-Cub $\mathbf{b}_{\mathbf{b i}}(\boldsymbol{X})$ can be converted to fluorine-free polymer electrolytes, which may endow $\mathbf{F i l m - C u b _ { b i }}(\boldsymbol{X})$ with more bio-compatibility.

\section{Conclusions}

We have succeeded in creating a self-standing polymer film having a hydrophilic gyroid minimal surface by cross-linking polymerization of an amphiphilic zwitterionic gemini monomer in a bicontinuous cubic liquid-crystalline assembly. This 
polymer film has the ability to absorb water molecules while maintaining the gyroid nanostructure until the gyroid minimal surface is fully covered by water molecules. Under these waterfulfilled conditions, the film shows high ionic conductivity in the order of $10^{-1} \mathrm{~S} \mathrm{~cm}^{-1}$ at room temperature, suggesting that the Grotthuss mechanism, a type of Newton's cradle phenomenon, occurs successively along the 3D continuous gyroid minimal surface over a long distance.

\section{Experimental section}

\section{Materials}

All the reagents were purchased from Sigma Aldrich and Tokyo Kasei corporation. The synthetic scheme for Diene-GZI is shown in the ESI. $\dagger$ The obtained compounds are characterized by ${ }^{1} \mathrm{H}$ $\mathrm{NMR},{ }^{13} \mathrm{C}$ NMR, and elemental analysis (see the ESI $\dagger$ ).

\section{Polymerization}

$1 \mathrm{wt} \%$ of DMPA is added as a photo-polymerization initiator. MX was sandwiched by a Teflon sheet and a cover glass with 130 $\mu \mathrm{m}$ thickness spacers. UV irradiation was performed for DMPAadded $\mathbf{M X}$ for $2 \mathrm{~h}$ at $30^{\circ} \mathrm{C}$ using a xenon lamp as a light source.

\section{Thermogravimetric analysis}

The samples of Film-Cub $\mathbf{b}_{\mathbf{b i}}$ were heated at 30, 80, 130, and 180 ${ }^{\circ} \mathrm{C}$ for 15 minutes, respectively. After that, their weights were measured immediately.

\section{Impedance measurement}

Alternating current impedance measurements were performed using a Schlumberger Solartron 1260 impedance analyzer (frequency range $=10 \mathrm{~Hz}$ to $10 \mathrm{MHz}$, applied voltage $=0.1 \mathrm{~V}$ ). Comb-shaped gold electrodes with a glass substrate were used as a cell for the measurements of ionic conductivity. To determine the cell constant of the cell, a $0.01 \mathrm{~mol} \mathrm{~L}^{-1} \mathrm{KCl}$ aqueous solution was employed as a calibration standard.

\section{Conflicts of interest}

There are no conflicts to declare.

\section{Acknowledgements}

T. I. is grateful for financial support from the Precursory Research for Embryonic Science and Technology (PRESTO) from the Japan Science and Technology Agency (JST) (no. JPMJPR1413). This work was also partially supported by the Foundation for the Promotion of Ion Engineering. T. K. is grateful for financial support from the JSPS Research Fellowships for Young Scientists (no. JP 18J21088). The authors thank Takahiro Kuzumaki in RIGAKU Corporation for the XRD measurements under various relative humidities. We are grateful to Dr N. Terill and O. Shebanova at I22, Diamond Light Source for help with SAXS experiments. The authors acknowledge funding for this work from the EPSRC (EP-K034308, EP-
P002250). Y. L. thanks the CSC for the stipend and the UoS for waiving the tuition fee.

\section{Notes and references}

1 K. D. Kreuer, J. Membr. Sci., 2001, 185, 29.

2 K. A. Mauritz and R. B. Moore, Chem. Rev., 2004, 104, 4535.

3 M. A. Hickner, H. Ghassemi, Y. S. Kim, B. R. Einsla and J. E. McGrath, Chem. Rev., 2004, 104, 4587.

4 B. Lafitte and P. Jannasch, Adv. Funct. Mater., 2007, 17, 2823.

5 B. Bae, T. Yoda, K. Miyatake, H. Uchida and M. Watanabe, Angew. Chem., Int. Ed., 2010, 49, 317.

6 P. Nimmanpipug, K. Kodchakorn, V. S. Lee, J. Yana, C. Jarumaneeroj, S. Phongtamrug and S. Chirachanchai, J. Polym. Sci., Part B: Polym. Phys., 2018, 56, 1625.

7 M. J. Park and N. P. Balsara, Macromolecules, 2010, 43, 292.

8 M. Michau and M. Barboiu, J. Mater. Chem., 2009, 19, 6124.

9 C.-F. Chow, V. A. L. Roy, Z. Ye, M. H. W. Lam, C. S. Lee and K. C. Lau, J. Mater. Chem., 2010, 20, 6245.

10 Y. Chen, M. Thorn, S. Christensen, C. Versek, A. Poe, R. C. Hayward, M. T. Tuominen and S. Thayumanavan, Nat. Chem., 2010, 2, 503.

11 S. Ueda, J. Kagimoto, T. Ichikawa, T. Kato and H. Ohno, Adv. Mater., 2011, 23, 3071.

12 T. Ichikawa, T. Kato and H. Ohno, J. Am. Chem. Soc., 2012, 134, 11354.

13 E. Tunkara, C. Albayrak, E. O. Polat, C. Kocabas and Ö. Dag, ACS Nano, 2014, 8, 11007.

14 Y. Nagao, Langmuir, 2017, 33, 12547.

15 J. A. Hurd, R. Vaidhyanathan, V. Thangadurai, C. I. Ratcliffe, I. L. Moudrakovski and G. K. H. Shimizu, Nat. Chem., 2009, 1, 705.

16 L. Cao, H. Wu, P. Yang, X. He, J. Li, Y. Li, M. Xu, M. Qiu and Z. Jiang, Adv. Funct. Mater., 2018, 28, 1804944.

17 P. Garstecki and R. Hołyst, Phys. Rev. E: Stat., Nonlinear, Soft Matter Phys., 2001, 64, 021501.

18 S. Diele, Curr. Opin. Colloid Interface Sci., 2002, 7, 333.

19 M. Impéror-Clerc, Curr. Opin. Colloid Interface Sci., 2005, 9, 370.

20 D. W. Bruce, Acc. Chem. Res., 2000, 33, 831.

21 C. Tschierske, Angew. Chem., Int. Ed., 2013, 52, 8828.

22 C. Tschierske and G. Ungar, ChemPhysChem, 2016, 17, 9.

23 S. Kutsumizu, Isr. J. Chem., 2012, 52, 844.

24 X. Zeng, G. Ungar and M. Impéror-Clerc, Nat. Mater., 2005, 4, 562.

25 T. Kato, M. Yoshio, T. Ichikawa, B. Soberats, H. Ohno and M. Funahashi, Nat. Rev. Mater., 2017, 2, 17001.

26 D. L. Gin, W. Gu, B. A. Pindzola and W.-J. Zhou, Acc. Chem. Res., 2001, 34, 973.

27 B.-K. Cho, RSC Adv., 2014, 4, 395.

28 B.-K. Cho, A. Jain, S. M. Gruner and U. Wiesner, Science, 2004, 305, 1598.

29 T. Ichikawa, M. Yoshio, A. Hamasaki, T. Mukai, H. Ohno and T. Kato, J. Am. Chem. Soc., 2007, 129, 10662.

30 D. L. Gin, X. Lu, P. R. Nemade, C. S. Pecinovsky, Y. Xu and M. Zhou, Adv. Funct. Mater., 2006, 16, 865. 
31 A. J. Boydston, C. S. Pecinovsky, S. T. Chao and C. W. Bielawski, J. Am. Chem. Soc., 2007, 129, 14550.

32 R. L. Kerr, S. A. Miller, R. K. Shoemaker, B. J. Elliott and D. L. Gin, J. Am. Chem. Soc., 2009, 131, 15972.

33 H. Zhang, L. Li, M. Möller, X. Zhu, J. J. Hernandez Rueda, M. Rosenthal and D. A. Ivanov, Adv. Mater., 2013, 25, 3543.

34 J. C. Shah, Y. Sadhale and D. M. Chilukuri, Adv. Drug Delivery Rev., 2001, 47, 229.

35 T. Kato, J. Uchida, T. Ichikawa and T. Sakamoto, Angew. Chem., Int. Ed., 2018, 57, 4355.

36 J. W. Goodby, I. M. Saez, S. J. Cowling, V. Görtz, M. Draper, A. W. Hall, S. Sia, G. Cosquer, S.-E. Lee and E. P. Raynes, Angew. Chem., Int. Ed., 2008, 47, 2754.

37 K. V. Axenov and S. Laschat, Materials, 2011, 4, 206.

38 K. Goossens, K. Lava, C. W. Bielawski and K. Binnemans, Chem. Rev., 2016, 116, 4643.

39 T. Ichikawa, K. Fujimura, M. Yoshio, T. Kato and H. Ohno, Chem. Commun., 2013, 49, 11746.

40 T. Kobayashi, T. Ichikawa, T. Kato and H. Ohno, Adv. Mater., 2017, 29, 1604429.

41 T. Ichikawa, A. Okafuji, T. Kato and H. Ohno, ChemistryOpen, 2016, 5, 439.

42 T. Matsumoto, A. Ono, T. Ichikawa, T. Kato and H. Ohno, Chem. Commun., 2016, 52, 12167.

43 A. Ono, H. Ohno, T. Kato and T. Ichikawa, Solid State Ionics, 2018, 317, 39.

44 D. J. Broer, C. M. W. Bastiaansen, M. G. Debije and A. P. H. J. Schenning, Angew. Chem., Int. Ed., 2012, 51, 7102.

45 U. Beginn, G. Zipp and M. Möller, Adv. Mater., 2000, 12, 510.

46 H.-K. Lee, H. Lee, Y. H. Ko, Y. J. Chang, N.-K. Oh, W.-C. Zin and K. Kim, Angew. Chem., Int. Ed., 2001, 40, 2669.

47 D. Yang, D. F. O'Brien and S. R. Marder, J. Am. Chem. Soc., 2002, 124, 13388.

48 B. A. Pindzola, J. Jin and D. L. Gin, J. Am. Chem. Soc., 2003, 125, 2940.

49 L. Y. Jin, J. Bae, J.-H. Ryu and M. Lee, Angew. Chem., Int. Ed., 2006, 45, 650.

50 M. Yoshio, T. Kagata, K. Hoshino, T. Mukai, H. Ohno and T. Kato, J. Am. Chem. Soc., 2006, 128, 5570.

51 D. Batra, D. N. T. Hay and M. A. Firestone, Chem. Mater., $2007,19,4423$.
52 T. Ichikawa, M. Yoshio, A. Hamasaki, J. Kagimoto, H. Ohno and T. Kato, J. Am. Chem. Soc., 2011, 133, 2163.

53 H. Takeuchi, T. Ichikawa, M. Yoshio, T. Kato and H. Ohno, Chem. Commun., 2016, 52, 13861.

54 M. Henmi, K. Nakatsuji, T. Ichikawa, H. Tomioka, T. Sakamoto, M. Yoshio and T. Kato, Adv. Mater., 2012, 24, 2238.

55 F. M. Menger and C. A. Littau, J. Am. Chem. Soc., 1993, 115, 10083.

56 M. Zhou, P. R. Nemade, X. Lu, X. Zeng, E. S. Hatakeyama, R. D. Noble and D. L. Gin, J. Am. Chem. Soc., 2007, 129, 9574.

57 E. S. Hatakeyama, B. R. Wiesenauer, C. J. Gabriel, R. D. Noble and D. L. Gin, Chem. Mater., 2010, 22, 4525.

58 G. P. Sorenson, K. L. Coppage and M. K. Mahanthappa, J. Am. Chem. Soc., 2011, 133, 14928.

59 G. P. Sorenson and M. K. Mahanthappa, Soft Mater., 2016, 12, 2408.

60 B. Guo, S. W. Tay, Z. Liu and L. Hong, Polymers, 2012, 4, 1499.

61 I. Nicotera, L. Coppola, C. O. Rossi, M. Youssry and G. A. Ranieri, J. Phys. Chem. B, 2009, 113, 13935.

62 A. Siu, J. Schmeisser and S. Holdcroft, J. Phys. Chem. B, 2006, 110, 6072.

63 H. Ohno, K. Fujita and Y. Kohno, Phys. Chem. Chem. Phys., 2015, 17, 14454.

64 T. Ueki and M. Watanabe, Macromolecules, 2008, 41, 3739.

65 K. D. Kreuer, S. J. Paddison, E. Spohr and M. Schuster, Chem. Rev., 2004, 104, 4637.

66 M. Armand and J. M. Tarascon, Nature, 2008, 451, 652.

67 A. J. Kim, M. S. Kaucher, K. P. Davis, M. Peterca, M. R. Imam, N. A. Christian, D. H. Levine, F. S. Bates, V. Percec and D. A. Hammer, Adv. Funct. Mater., 2009, 19, 2930.

68 E. B. Trigg, T. W. Gaines, M. Maréchal, D. E. Moed, P. Rannou, K. B. Wagener, M. J. Stevens and K. I. Winey, Nat. Mater., 2018, 17, 725.

69 A. Kusoglu and A. Z. Weber, Chem. Rev., 2017, 117, 987.

70 Z. Cao, Y. Peng, T. Yan, S. Li, A. Li and G. A. Voth, J. Am. Chem. Soc., 2010, 132, 11395.

71 D. Muonz-Santiburcio, C. Wittekindt and D. Marx, Nat. Commun., 2013, 4, 2349.

72 The molecular structure of N-MZI is shown in the ESI. $\dagger$ 